\title{
A modified technique to improve the outcome of intubation with a left-sided double-lumen endobronchial tube
}

Hung-Te Hsu' ${ }^{1,2}$, Shah-Hwa Chou ${ }^{4,5}$, Chun-Yen Chou' ${ }^{1}$ Kuang-Yi Tseng ${ }^{1,2}$, Yi-Wei Kuo ${ }^{1}$, Mei-Chun Chen ${ }^{1}$ and Kuang-l Cheng ${ }^{1,3^{*}}$

\begin{abstract}
Background: The use of a video-assisted laryngoscope $(V L)$ has been shown to reduce the time to achieve intubation with a double-lumen endobronchial tube (DLT). As the blade of the VL is curved differently to a standard laryngoscope, the DLT must be angled into a hockey stick shape to fit properly. We conducted a study to establish which direction of angulation was best to facilitate correct positioning of the DLT when using a VL.

Methods: We enrolled patients scheduled for thoracic surgery who required intubation with a DLT. They were prospectively randomized into one of two groups: those intubated with a DLT angled to conceal the tracheal orifice (the tracheal orifice-covered, TOC) group or the tracheal orifice-exposed (TOE) group. The composite primary outcome measures were time taken to intubate and the frequency of first-time success. The time taken to intubate was divided into: $\mathrm{T1}$, the time from mouth opening to visualization of the vocal cords with the $\mathrm{VL}$; and $\mathrm{T} 2$, the time taken to advance the DLT through the cords until its tip lay within the trachea and three carbon dioxide waveforms had been detected by capnography. The hemodynamic responses to intubation and intubation-related adverse events were also recorded.
\end{abstract}

Results: Sixty-six patients completed the study, with 33 in each group. Total intubation time was significantly shorter in the TOC group (mean $30.6 \pm$ standard deviation 2.7 seconds versus $38.7 \pm 3.3$ seconds, $\mathrm{p}<0.0001$ ). T2 was also significantly shorter in the TOC group than the TOE group $(27.2 \pm 2.5$ seconds versus $34.9 \pm 3.0$ seconds, $p<0.0001)$. The severity of hoarseness on the first postoperative day and sore throat on the fourth postoperative day were significantly lower in the TOC group than the TOE group ( $p=0.02$ and $<0.0001$, respectively). The hemodynamic responses to intubation were broadly similar between the groups.

Conclusion: When placing a left-sided DLT using a VL, angling the bronchial lumen to a hockey stick shape that conceals the tracheal lumen saves time and ameliorates the severity of post-intubation complications.

Trial registration: ClinicalTrials.gov Identifier: NCT01605591.

Keywords: Left-sided double-lumen endobronchial tube, Video-assisted Laryngoscope, Angling

\footnotetext{
* Correspondence: 770234kmuhanesthesia@gmail.com

'Department of Anesthesiology, Kaohsiung Medical University Hospital,

No.100 Ziyou 1st Rd., Sanmin District, Kaohsiung 807, Taiwan, Republic of

China

${ }^{3}$ Faculty of Anesthesiology, College of Medicine, Kaohsiung Medical

University, Kaohsiung 807, Taiwan, Republic of China

Full list of author information is available at the end of the article
} 


\section{Background}

A double-lumen endobronchial tube (DLT) is often needed to facilitate one-lung ventilation in patients undergoing surgical procedures involving the chest cavity [1-3]. A DLT not only provides independent ventilation for each lung but also allows bronchial toilet without interrupting ventilation [4]. However, owing to its larger size and more complex design than single-lumen endotracheal tube (SLT), anesthesiologists can find intubation with a DLT challenging, even in a patient with a normal airway. A DLT is relatively contraindicated in a patient with a difficult airway [5].

In recent years several video-assisted laryngoscopes, such as the GlideScope video laryngoscope (GVL; Verathon, Bothell, WA), have been developed, and have been shown to reduce the time taken to intubate with a DLT [6]. Nonetheless, the DLT must be angulated to fit the curve of the GVL's blade, and the incidence of the common complications of tracheal intubation, such as hoarseness and sore throat, appear not to be reduced [7]. This may be a consequence not only of the larger size and more complex structure of the DLT, but also of intubation technique. Bustamante and colleagues reported that sequential rotation of the DLT facilitated its advancement into the trachea [8], but a method of angulation has also been reported [9].

We hypothesized that making intubation with a DLT more straightforward would shorten the time to achieve intubation and reduce the incidence or severity of postintubation complications. We identified two methods of angulating the DLT to facilitate intubation, and examined which was most effective. We also recorded the hemodynamic response to intubation, and the incidence of post-intubation complications, such as hoarseness and sore throat.

\section{Methods \\ Patients}

The study protocol was approved by the Institutional Research Board of Kaohsiung Medical University Hospital (reference number KMUH-IRB-20110172) and all patients gave written informed consent. The study was registered at ClinicalTrails.Gov with the number NCT01605591. Patients who were categorized as having American Society of Anesthesiologists (ASA) physical status I-III, who were 20 years of age or over, and who required one-lung ventilation for thoracic surgery were enrolled in this study. Patients with limited understanding of the local language or learning difficulties, were scheduled for surgery likely to take over 6 hours, had a history of gastroesophageal reflux, were pregnant, were scheduled for tracheostomy or who were undergoing postoperative ventilation in the intensive care unit (ICU) were excluded. In addition, patients in whom predictors of difficult intubation were detected- including limited mouth opening $(<3 \mathrm{~cm})$, limited neck extension $\left(<35^{\circ}\right)$, a thyromental distance $<6 \mathrm{~cm}$ or sternomental distance $<12.5 \mathrm{~cm}$ at full head extension-were also excluded [10]. Two board-certified anesthesiologists, who had performed at least 300 tracheal intubations with the GVL, undertook all DLT intubations.

\section{Induction and intubation}

Routine monitoring was established in the operating room (OR), and a radial artery catheter placed to monitor arterial pressure. Patients were randomly assigned to the tracheal orifice-concealed group (TOC Group) or the tracheal orifice-exposed group (TOE Group) by computergenerated codes that were kept in sealed opaque envelopes. Patients, and the anesthesiologists who collected the postoperative data, were blinded to the randomization allocation.

In the TOE group, the distal $8-10 \mathrm{~cm}$ portion of a left-sided DLT (Broncho-Cath ; Mallinckrodt, St. Louis, MO) was angulated approximately $90^{\circ}$ to the left using the bespoke DLT-malleable stylet (Mallinckrodt) inserted through the bronchial lumen (Figure 1A) [8]. In the TOC group, the distal portion of a left-sided DLT was angulated to the right to obscure the distal orifice of the tracheal lumen (Figure 1B). After angulation, the DLT resembled a hockey stick.

After pre-oxygenation, anesthesia was induced with intravenous thiamylal $\left(5 \mathrm{mg} \cdot \mathrm{kg}^{-1}\right)$ and fentanyl $\left(2 \mu \mathrm{g} \cdot \mathrm{kg}^{-1}\right)$ and intubation was facilitated with intravenous cisatracurium $\left(0.15 \sim 0.2 \mathrm{mg} \cdot \mathrm{kg}^{-1}\right)$. Propofol was administered (1.0 mg.kg ${ }^{-1}$ ) before intubation to blunt the hemodynamic response to laryngoscopy, and manipulation of the upper airway and trachea. Left-sided endobronchial DLT intubation was undertaken with a GVL in all cases. The bronchial and tracheal cuffs of the DLT were thinly lubricated with a sterile surgical lubricant (Surgilube, E Fougera, Melville, NY).

In the TOE group, the tracheal orifice was aligned with the convex aspect of the angulated DLT. After the endobronchial tube tip had entered the trachea, the stylet was removed from the bronchial lumen. An initial $180^{\circ}$ counterclockwise rotation was performed to facilitate smooth advancement of the DLT through the vocal cords. Next, an additional $90^{\circ}$ clockwise rotation was performed to align the tube with the left main bronchus, and the DLT was advanced until resistance was encountered [8].

In the TOC group, the tracheal orifice was aligned with the concave aspect of the DLT. The DLT was advanced directly through the vocal cords, the stylet was removed, and then the DLT was advanced gently while rotating in a $90^{\circ}$ clockwise direction until resistance was felt. Successful intubation was confirmed by a series of three complete respiratory cycles detected by capnography and bilateral 

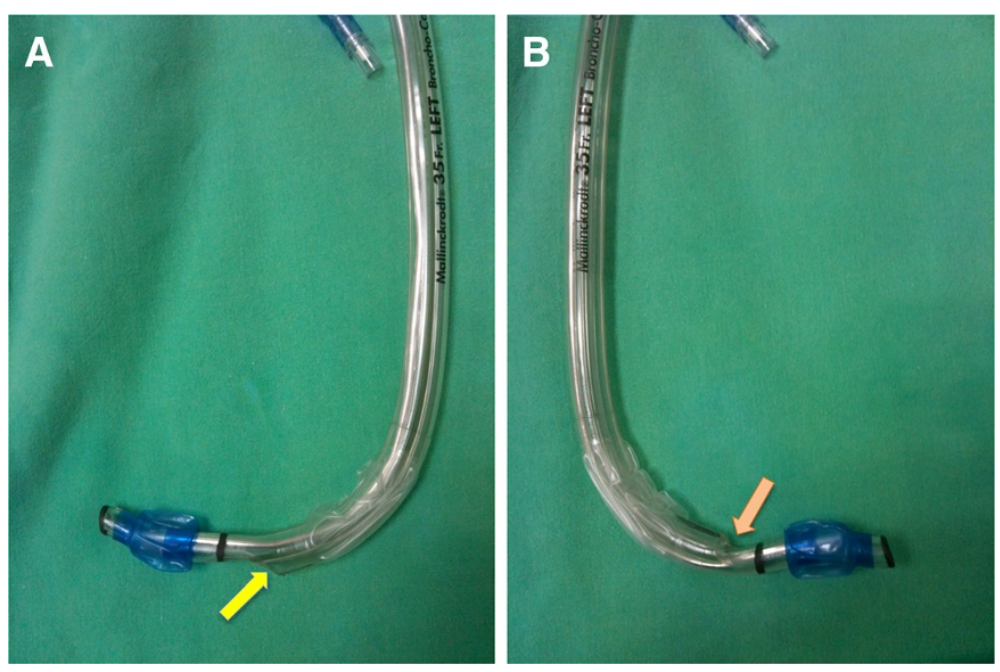

Figure 1 Directions of angulation of the double-lumen endobronchial tube. A. Angulation leaving the tracheal orifice exposed (TOE group). B. Angulation concealing the tracheal orifice (tracheal orifice concealed, TOC group). The distal tracheal orifice is indicated by the arrow.

chest auscultation. Later, correct bronchial placement was confirmed with a flexible bronchoscope.

\section{Outcome measures}

Success at the first attempt of intubation was recorded by an independent observer. The total time taken for DLT intubation was calculated from the time when the GVL's blade tip passed between the patient's lips to the completion of three respiratory cycles displayed on the capnograph. This time was subdivided into: $\mathrm{T} 1$, the time from the tip of the blade passing between the patient's lips to identification of the vocal cords; and T2, the time from identification of the vocal cords to the completion of three respiratory cycles displayed on the capnograph. After the blade of the GVL was removed, it was examined for blood on its surface. Mean blood pressure and heart rate were recorded in the OR before induction of anesthesia (baseline), pre-intubation (pre-I) and 1, 3 and 5 minutes post-intubation (post-I1, post-I3 and post-I5, respectively). The oral cavity, pharynx and larynx were examined by an otolaryngologist (blinded to the type of DLT-angulation method) 5 minutes after intubation for signs of lacerations or bleeding. At the end of surgery, the tube was removed when spontaneous tidal volumes exceeded $5 \mathrm{ml} \cdot \mathrm{kg}^{-1}[11]$ and the patient was responding to simple verbal commands. On the first four postoperative days, another independent anesthesiologist (blinded to group allocation) recorded the extent of hoarseness, sore throat and odynophagia. Participants scored sore throat and odynophagia on a visual analog scale from 0 , indicating 'none' to 10: scores above 0 were subsequently categorized as mild (1-3), moderate (4-6) or severe (7-10). Hoarseness was classified as absent (0), subjective (1), observed by the anesthesiologist (2) or aphonic (3).
We defined bronchospasm as prolonged expiration with wheeze and rising end tidal $\mathrm{CO}_{2}$ in the presence of increased airway pressures, desaturation or a falling tidal volume [12]. Arrhythmia was defined as any ventricular or supraventricular premature beats or any sustained rhythm other than sinus rhythm. Arrhythmias that appeared for the first time or increased in frequency by at least four beats per minute were attributed to intubation if observed within 2 minutes of laryngoscopy [13].

\section{Statistical analysis}

We planned to determine variables from independent control and experimental subjects with one control per experimental subject, according to our pilot data, in order to detect a mean difference in time for intubation of 9.2 seconds (20\% mean difference) with a standard deviation of 11 seconds. A priori power analysis revealed that 31 participants were needed in each group to detect a difference with a power of 0.9 at an $\alpha$-level of 0.05 . Student's $t$-test, the chi-squared test and Fisher's exact test were used to compare the groups. In addition, hemodynamic data, such as heart rate and blood pressure, were analyzed with repeated-measure analysis of variance (ANOVA) for intra- and intergroup comparisons. Bonferroni's post hoc tests were undertaken where appropriate. Data are presented as the mean \pm standard deviation, or the number and proportion as appropriate. SPSS 17.0 software (Apache Software Foundation, Forest Hill, MD, USA) was used for all statistical analyses.

\section{Results}

Two hundred fifty-one patients undergoing thoracic surgery were approached to participate in the study, but 181 did not meet the inclusion criteria. Of these, 28 were less 
than 20 years old, 13 were assessed to have a difficult airway, 10 declined to participate, 25 required prolonged intubation on the ICU, and 105 could not give informed consent (15 due to reduced level of consciousness and 90 who had an inadequate understanding of the local language). Ultimately, 70 patients were enrolled, but four were excluded from the final analysis owing to an operating time greater than 6 hours (two from each group, Figure 2). The data of 66 patients were subject to final analysis. The clinical and demographic characteristics of each group were broadly comparable (Table 1 ). There were no significant differences between the upper airway characteristics of each group, i.e., the modified Mallampati classification, thyromental distance and the vertical distance between the upper and lower incisors during active and passive mouth opening (Table 2).

The first-attempt success rate for DLT intubation in both groups was $100 \%$. The mean total intubation time was significantly shorter in the TOC group than the TOE group ( $30.6 \pm 2.7$ seconds versus $38.7 \pm 3.3$ seconds, respectively; $\mathrm{p}<0.0001$, Table 3 ). Although there was no significant difference in T1 between the groups, T2 was significantly shorter in the TOC group than the TOE group $(27.2 \pm 2.5$ seconds versus $34.9 \pm 3.0$ seconds, respectively; $\mathrm{p}<0.001)$. Peripheral oxygen saturation was maintained at $99-100 \%$ in all patients during intubation.

The incidence of hoarseness was broadly comparable between the groups, but the severity of hoarseness on

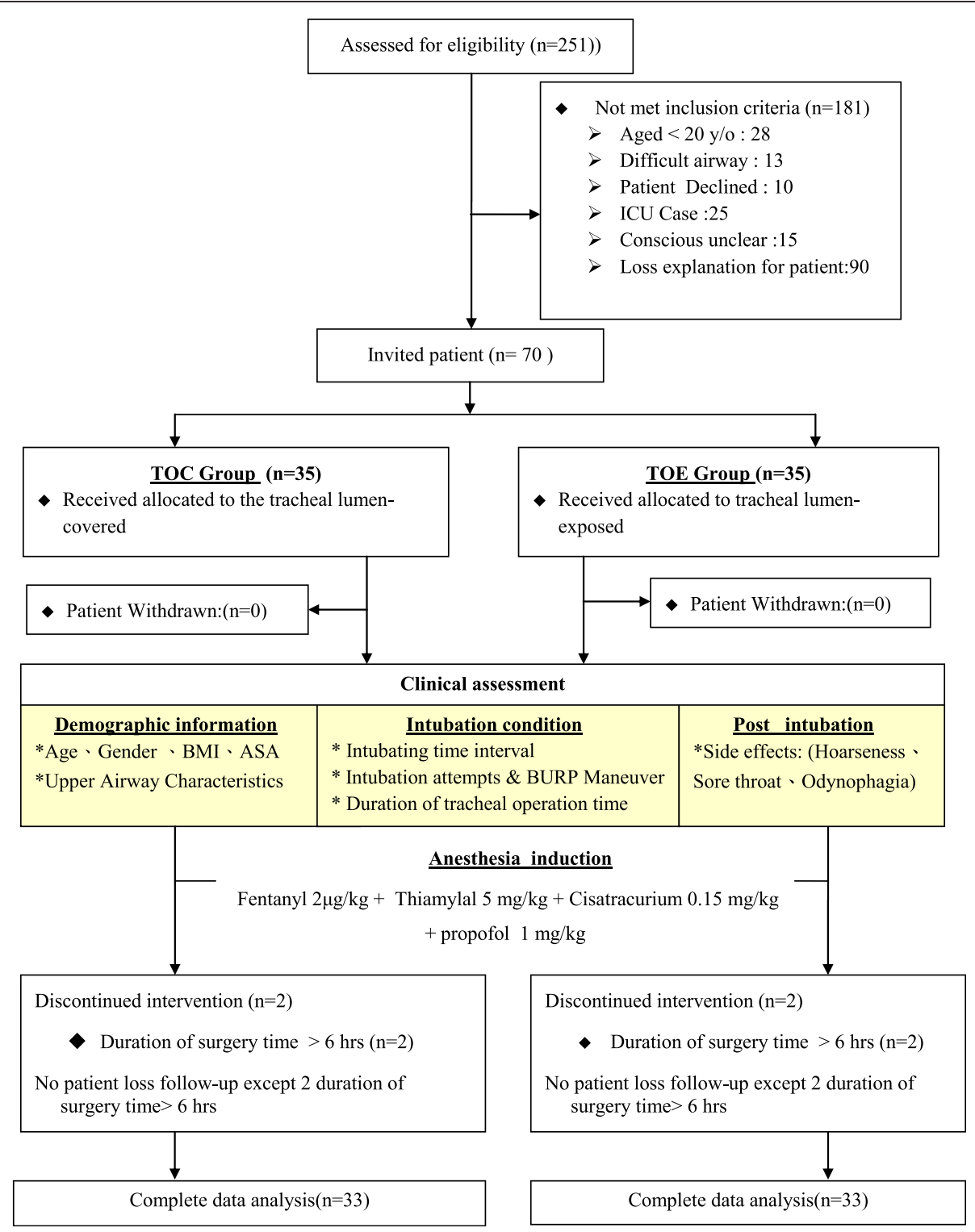

Figure 2 Study flow diagram. 
Table 1 Patients' demographic and clinical characteristics

\begin{tabular}{llll}
\hline & $\begin{array}{l}\text { TOE Group } \\
(\mathbf{n = 3 3 )}\end{array}$ & $\begin{array}{l}\text { TOC Group } \\
(\mathbf{n}=\mathbf{3 3})\end{array}$ & P valv \\
\hline Age (years) & $40.1 \pm 18.7$ & $36.1 \pm 16.8$ & 0.364 \\
Weight $(\mathrm{kg})$ & $60.3 \pm 10.1$ & $60.7 \pm 12.4$ & 0.895 \\
Height $(\mathrm{cm})$ & $166.2 \pm 9.8$ & $167.0 \pm 10.6$ & 0.750 \\
BMI (kg.m ${ }^{-2}$ ) & $21.7 \pm 3.5$ & $21.8 \pm 4.1$ & 0.936 \\
ASA physical status & & & \\
I/II/II & $0 / 22 / 11$ & $0 / 21 / 12$ & $>0.999$ \\
Sex & & & \\
Male : Female & $22: 11$ & $20: 13$ & 0.798
\end{tabular}

Data are expressed as the mean \pm standard deviation where appropriate. Abbreviations: TOE tracheal orifice exposed, TOC tracheal orifice concealed, $B M I$ body mass index, ASA American Society of Anesthesiologists.

the first postoperative day was lower in the TOC group $(p=0.02$, Table 4). The incidence of sore throat was also comparable between the groups, but the severity of sore throat was lower in the TOC group on the fourth postoperative day $(p<0.0001$, Table 5$)$. There was no difference in the incidence or severity of odynophagia (Table 6). No patient in either group had episodes of bronchospasm or post-intubation arrhythmia lasting 2 minutes or more.

There were no significant differences in the hemodynamic response to intubation between the groups. Heart rate and mean arterial pressure increased significantly 1 minute after intubation in both groups. Mean arterial pressure had returned to baseline by 3 minutes and was lower than baseline 5 minutes after tracheal intubation in both groups.

\section{Discussion}

The size and structure of a DLT can make it difficult to place correctly when using a VL, reducing the chances of success, prolonging intubation and increasing the risk of adverse events compared with an SLT either with direct laryngoscopy [14] or with a GVL $[6,15]$. This study followed on from our previous research [3], which

Table 2 Patients' upper airway characteristics

\begin{tabular}{llll}
\hline & $\begin{array}{l}\text { TOE Group } \\
(\mathbf{n}=\mathbf{3 3})\end{array}$ & $\begin{array}{l}\text { TOC Group } \\
(\mathbf{n}=\mathbf{3 3})\end{array}$ & P valve \\
\hline Mouth opening $(\mathrm{cm})$ & & & \\
active & $4.7 \pm 0.7$ & $4.5 \pm 0.7$ & 0.470 \\
passive & $3.9 \pm 0.5$ & $4.0 \pm 0.50$ & 0.429 \\
Thyromental distance $(\mathrm{cm})$ & $8.8 \pm 1.0$ & $8.8 \pm 1.0$ & 0.844 \\
Mallampati score & & & \\
I/II/II/IV & $17 / 9 / 7 / 0$ & $13 / 15 / 5 / 0$ & 0.321 \\
Cormack-Lehane grade & & & \\
I/II/III/IV & $23 / 7 / 3 / 0$ & $23 / 7 / 2 / 0$ & $>0.999$ \\
\hline
\end{tabular}

Data are expressed as the mean \pm standard deviation where appropriate. Abbreviations: TOE tracheal orifice exposed, TOC tracheal orifice concealed.
Table 3 Intubation data

\begin{tabular}{llll}
\hline & $\begin{array}{l}\text { TOE Group } \\
(\mathbf{n}=\mathbf{3 3})\end{array}$ & $\begin{array}{l}\text { TOC Group } \\
(\mathbf{n}=\mathbf{3 3})\end{array}$ & P-value \\
\hline $\begin{array}{l}\text { Time to achieve } \\
\text { intubation (sec) }\end{array}$ & & & \\
T1 & $3.7 \pm 1.6$ & $3.4 \pm 0.8$ & 0.278 \\
T2 & $34.9 \pm 3.0$ & $27.2 \pm 2.5$ & $<0.0001$ \\
T Total & $38.7 \pm 3.3$ & $30.6 \pm 2.7$ & $<0.0001$ \\
$\begin{array}{l}\text { Number of intubation } \\
\text { attempts: } \mathbf{1 / 2 / 3}\end{array}$ & $33 / 0 / 0$ & $33 / 0 / 0$ & 1 \\
$\begin{array}{l}\text { BURP maneuver Yes/No } \\
\begin{array}{l}\text { Duration of tracheal } \\
\text { operation time (min) }\end{array}\end{array}$ & $0 / 33$ & $0 / 33$ & 1 \\
\hline $\begin{array}{l}\text { Data are expressed as the mean } \pm \text { standard deviation where appropriate. } \\
\text { Abbreviations: TOE tracheal orifice exposed, TOC tracheal orifice concealed, } \\
\text { BURP backward upward rightward pressure. }\end{array}$ &
\end{tabular}

showed that DLT intubation is straightforward when using a GVL in patients with a normal airway. In this study we found that angulating the DLT to conceal the orifice of the tracheal lumen in its concave aspect reduced the total time for intubation by facilitating the advancement of the DLT into the glottic inlet and reducing the need for rotation, while also reducing the incidence of postoperative hoarseness.

We also found that intubating with the TOE technique using sequential rotation had some disadvantages. First, rotating the DLT $180^{\circ}$ clockwise increases the friction between the tracheal cuff and the vocal cords. Second, during rotation, the bevel of the tracheal orifice may

Table 4 Hoarseness

\begin{tabular}{|c|c|c|c|}
\hline & $\begin{array}{l}\text { TOE Group } \\
(n=33)\end{array}$ & $\begin{array}{l}\text { TOC Group } \\
(n=33)\end{array}$ & P-value \\
\hline \multicolumn{4}{|l|}{ Postoperative day 1} \\
\hline Incidence & $17(51.5 \%)$ & $12(36.4 \%)$ & 0.229 \\
\hline $\begin{array}{l}\text { Severity (none/mild/ } \\
\text { moderate/severe) }\end{array}$ & $16 / 9 / 6 / 2$ & $22 / 11 / 0 / 0$ & 0.020 \\
\hline \multicolumn{4}{|l|}{ Postoperative day 2} \\
\hline Incidence & $5(15.2 \%)$ & $5(15.2 \%)$ & 1 \\
\hline $\begin{array}{l}\text { Severity (none/mild/ } \\
\text { moderate/severe) }\end{array}$ & $28 / 4 / 1 / 0$ & $28 / 5 / 0 / 0$ & $>0.999$ \\
\hline \multicolumn{4}{|l|}{ Postoperative day 3} \\
\hline Incidence & $1(3.0 \%)$ & $2(6.0 \%)$ & $>0.999$ \\
\hline $\begin{array}{l}\text { Severity (none/mild/ } \\
\text { moderate/severe) }\end{array}$ & $32 / 0 / 1 / 0$ & $31 / 2 / 0 / 0$ & 0.239 \\
\hline \multicolumn{4}{|l|}{ Postoperative day 4} \\
\hline Incidence & $1(3.0 \%)$ & $0(0 \%)$ & $>0.999$ \\
\hline $\begin{array}{l}\text { Severity (none/mild/ } \\
\text { moderate/severe) }\end{array}$ & $32 / 1 / 0 / 0$ & $33 / 0 / 0 / 0$ & $>0.999$ \\
\hline Overall incidence & $18(54.6 \%)$ & $14(42.4 \%)$ & 0.460 \\
\hline
\end{tabular}

Data are expressed as the number with the proportion in parentheses where appropriate.

Abbreviations: TOE tracheal orifice exposed, TOC tracheal orifice concealed. 
Table 5 Sore throat

\begin{tabular}{|c|c|c|c|}
\hline & $\begin{array}{l}\text { TOE Group } \\
(\mathrm{n}=33)\end{array}$ & $\begin{array}{l}\text { TOC Group } \\
(\mathrm{n}=33)\end{array}$ & P-value \\
\hline \multicolumn{4}{|l|}{ Postoperative day 1} \\
\hline Incidence & $12(36.4 \%)$ & $5(15.2 \%)$ & 0.422 \\
\hline $\begin{array}{l}\text { Severity (none/mild/ } \\
\text { moderate/severe) }\end{array}$ & $21 / 11 / 0 / 1$ & 28/5/0/0 & 0.090 \\
\hline \multicolumn{4}{|l|}{ Postoperative day 2} \\
\hline Incidence & $8(24.2 \%)$ & 7 (21.2\%) & 0.551 \\
\hline $\begin{array}{l}\text { Severity (none/mild/ } \\
\text { moderate/severe) }\end{array}$ & 25/7/1/0 & 26/7/0/0 & $>0.999$ \\
\hline \multicolumn{4}{|l|}{ Postoperative day 3} \\
\hline Incidence & $1(3.0 \%)$ & $3(9.1 \%)$ & 0.613 \\
\hline $\begin{array}{l}\text { Severity (none/mild/ } \\
\text { moderate/severe) }\end{array}$ & $32 / 0 / 1 / 0$ & $30 / 3 / 0 / 0$ & 0.239 \\
\hline \multicolumn{4}{|l|}{ Postoperative day 4} \\
\hline Incidence & $2(6.1 \%)$ & $0(0 \%)$ & 0.492 \\
\hline $\begin{array}{l}\text { Severity (none/mild/ } \\
\text { moderate/severe) }\end{array}$ & $31 / 2 / 0 / 0$ & $33 / 0 / 0 / 0$ & $<0.0001$ \\
\hline Overall incidence & $16(48.4 \%)$ & $11(33.3 \%)$ & 0.317 \\
\hline
\end{tabular}

injure one vocal cord or dislocate the arytenoid cartilages [16]. Although rotation was accomplished under direct vision with the GVL, minor injuries of the vocal folds are difficult to avoid and detect after surgery [17]. Our modified technique used in the TOC group showed three

Table 6 Odynophagia

\begin{tabular}{llll}
\hline & $\begin{array}{l}\text { TOE Group } \\
(\mathbf{n}=\mathbf{3 3})\end{array}$ & $\begin{array}{l}\text { TOC Group } \\
(\mathbf{n}=33)\end{array}$ & P-value \\
\hline $\begin{array}{l}\text { Postoperative day } \mathbf{1} \\
\text { Incidence }\end{array}$ & $15(45.4 \%)$ & $10(30.3 \%)$ & 0.310 \\
$\begin{array}{l}\text { Severity (none/mild/ } \\
\text { moderate/severe) }\end{array}$ & $18 / 12 / 2 / 1$ & $23 / 9 / 1 / 0$ & 0.457 \\
$\begin{array}{l}\text { Postoperative day } 2 \\
\text { Incidence }\end{array}$ & $3(9.1 \%)$ & $3(9.1 \%)$ & 1 \\
$\begin{array}{l}\text { Severity (none/mild/ } \\
\text { moderate/severe) }\end{array}$ & $30 / 3 / 0 / 0$ & $33 / 3 / 0 / 0$ & 1 \\
$\begin{array}{l}\text { Postoperative day } 3 \\
\text { Incidence }\end{array}$ & $2(6.1 \%)$ & $1(3.0 \%)$ & $>0.999$ \\
$\begin{array}{l}\text { Severity (none/mild/ } \\
\text { moderate/severe) }\end{array}$ & $31 / 2 / 0 / 0$ & $32 / 1 / 0 / 0$ & $>0.999$ \\
$\begin{array}{l}\text { Postoperative day } 4 \\
\text { Incidence }\end{array}$ & $1(3.0 \%)$ & $0(0 \%)$ & $>0.999$ \\
$\begin{array}{l}\text { Severity (none/mild/ } \\
\text { moderate/severe) }\end{array}$ & $32 / 1 / 0 / 0$ & $33 / 0 / 0 / 0$ & $>0.999$ \\
Overall incidence & $16(48.5 \%)$ & $12(36.4 \%)$ & 0.334 \\
\hline
\end{tabular}

Data are expressed as the number with the proportion in parentheses where appropriate.

Abbreviations: TOE tracheal orifice exposed, TOC tracheal orifice concealed. advantages: 1) intubation was straightforward; 2) the $180^{\circ}$ clockwise rotation of the DLT was not necessary, decreasing friction against the vocal cords; and 3) no abrasion or avulsion injuries to the vocal cords or laryngeal tissues were observed. All would be likely to have contributed to the lower incidence of post-intubation complications.

Hernandez and colleagues have described an alternative technique of intubating with a DLT using a GVL [9]: our technique differs in three ways. First, we angulated the DLT $8-10 \mathrm{~cm}$ from the distal tip, compared with 12 $16 \mathrm{~cm}$ in the Hernandez study, allowing the DLT to be maneuvered backwards and forwards more easily. Second, we angulated the DLT by $90^{\circ}$ into the shape of a hockey stick, while Hernandez angulated the DLT by $60^{\circ}$; with our technique the DLT could be advanced into the trachea smoothly and it did not get stuck. Third, we withdrew the stylet in one movement when the tracheal orifice had passed through the glottis, whereas Hernandez and colleagues withdrew the stylet in two stages. Our results show that our modified technique with a GVL is a practical and feasible technique.

The results of our study confirmed our hypothesis. Compared with the TOC group, the mean time to achieve intubation was approximately 8 seconds longer in the TOE group. This was due to the sequential rotation of the DLT in the TOE group, especially the initial $180^{\circ}$ clockwise rotation. In our experience, if rotation is too fast, the DLT might slide out of the glottis and injure surrounding soft tissues; rotation of the DLT must be gentle, careful and gradual.

The severity of hoarseness was lower on the first postoperative day, and sore throat was less severe on the fourth postoperative day in the TOC group, although there were no other statistically significant differences. The large size and complicated structure of the DLT is a plausible explanation for these complications. Stout et al. [18] reported that the incidence and severity of postoperative hoarseness and sore throat directly correlated with the size of the endotracheal tube. The sizes of DLT used in our study were 35 and $37 \mathrm{Fr}$, relatively larger than a standard SLT, suggesting that the size of the tube is the most important risk factor. Even though we simplified the intubation procedure, it is impossible to avoid all contact between the cuffs of the DLT and the vocal cords during intubation, so there may still be an element of trauma to the laryngeal tissues that could cause hoarseness. Finally, laryngeal trauma may also have occurred during surgery and extubation [19]; the angulated DLT could have injured the vocal cords when it was removed.

The hemodynamic response to DLT intubation was comparable between the groups. Han et al. reported that using a modified technique for orotracheal SLT intubation with a GVL made intubation quicker but did not ameliorate the adverse hemodynamic response [20]. 
However, there are few data concerning the hemodynamic response to laryngoscopy with a GVL when intubating with a DLT. Our previous studies found only small differences in the hemodynamic response to intubation when using a video-assisted airway device compared with direct laryngoscopy $[6,21]$. The size and structure of the DLT also likely explain these observations. Another option to blunt stimulation of the cardiovascular system before intubation is the preemptive use of drugs such as alfentanil or remifentanil.

Our study had some limitations. First, all our patients had normal airways and our study did not establish the safety and efficacy of angulating the DLT in patients with difficult airways, or limited mouth opening or neck movement. Second, the mean body mass index (BMI) of our patients was within the normal range. Holmberg et al. [20] have reported that morbidly obese patients (those with a BMI $>40 \mathrm{~kg} \cdot \mathrm{m}^{-2}$ ) are more difficult to intubate. Third, none of the patients had a history of hypertension, so we were not able to draw any conclusions about the influence of hypertension on intubation with a DLT. Finally, it is not clear whether our findings can be generalized to other types of DLT, such as right-sided DLTs or the Carlens DLT (SUMI ${ }^{\circ}$, Portex, St Paul, MN).

\section{Conclusions}

In conclusion, when intubating a patient with a leftsided DLT using a GVL, angling the bronchial lumen into a hockey stick shape with the tracheal lumen concealed saves intubation time and reduces the severity of post-intubation complications, but does not ameliorate the hemodynamic response. We recommend using this method when intubating patients with a leftsided DLT.

\section{Competing interests}

The authors declare that they have no competing interests.

\section{Authors' contributions \\ HTH, the study designer, carried out the clinical studies, analyzed and interpreted the data, as well as drafted the manuscript. SHC, the study designer, carried out the clinical studies, and revised the manuscript critical for important intellectual content. CYC carried out the clinical studies, and acquired the data. KYT carried out the clinical studies, and acquired the data. YWK carried out the clinical studies, and acquired the data. MCC carried out the clinical studies, and acquired the data. KIC, the major study designer, carried out the clinical studies, and drafted the manuscript. All authors read and approved the final manuscript.}

\section{Acknowledgment}

We thank Dr. Zhen-Yu Jane (Department of Otorhinolaryngology, Kaohsiung Medical University Hospital, Taiwan) for the examination of the patients. No external funding and no competing interests are declared.

\section{Funding}

Department of Anesthesiology, Kaohsiung Medical University.

\section{Author details}

'Department of Anesthesiology, Kaohsiung Medical University Hospital, No.100 Ziyou 1st Rd., Sanmin District, Kaohsiung 807, Taiwan, Republic of
China. ${ }^{2}$ Graduate Institute of Medicine, College of Medicine, Kaohsiung Medical University, Kaohsiung 807, Taiwan, Republic of China. ${ }^{3}$ Faculty of Anesthesiology, College of Medicine, Kaohsiung Medical University, Kaohsiung 807, Taiwan, Republic of China. ${ }^{4}$ Department of Chest Surgery, Kaohsiung Medical University Hospital, Kaohsiung 807, Taiwan, Republic of China. ${ }^{5}$ School of Medicine, College of Medicine, Kaohsiung Medical University, Kaohsiung 807, Taiwan, Republic of China.

Received: 18 January 2014 Accepted: 13 August 2014

Published: 18 August 2014

\section{References}

1. Campos JH: Progress in lung separation. Thorac Surg Clin 2005, 15(1):71-83.

2. Cohen E: Management of one-lung ventilation. Anesthesiol Clin North America 2001, 19(3):475-495. vi.

3. Benumof JL, Partridge BL, Salvatierra C, Keating J: Margin of safety in positioning modern double-lumen endotracheal tubes. Anesthesiology 1987, 67(5):729-738.

4. Lewis JW Jr, Serwin JP, Gabriel FS, Bastanfar M, Jacobsen G: The utility of a double-lumen tube for one-lung ventilation in a variety of noncardiac thoracic surgical procedures. J Cardiothorac Vasc Anesth 1992, 6(6):705-710.

5. Campos JH: Lung isolation techniques for patients with difficult airway. Curr Opin Anaesthesiol 2010, 23(1):12-17.

6. Hsu HT, Chou SH, Wu PJ, Tseng KY, Kuo YW, Chou CY, Cheng Kl: Comparison of the GlideScope(R) videolaryngoscope and the Macintosh laryngoscope for double-lumen tube intubation. Anaesthesia 2012, 67(4):411-415.

7. Russell $T$, Slinger P, Roscoe A, McRae K, Van Rensburg A: A randomised controlled trial comparing the GlideScope((R)) and the Macintosh laryngoscope for double-lumen endobronchial intubation. Anaesthesia 2013, 68(12):1253-1258.

8. Bustamante S, Parra-Sanchez I, Apostolakis J: Sequential rotation to insert a left double-lumen endotracheal tube using the GlideScope. Can $J$ Anaesth 2010, 57(3):282-283.

9. Hernandez AA, Wong DH: Using a Glidescope for intubation with a double lumen endotracheal tube. Can J Anaesth 2005, 52(6):658-659.

10. Chapter 5. Airway Management. In Morgan's Clinical Anesthesiology. 4th edition. Edited by Morgan GE, Mikhail MS, Murray MJ. The McGraw-Hill Companies, Inc; 2006.

11. Marelich GP, Murin S, Battistella F, Inciardi J, Vierra T, Roby M: Protocol weaning of mechanical ventilation in medical and surgical patients by respiratory care practitioners and nurses: effect on weaning time and incidence of ventilator-associated pneumonia. Chest 2000, 118(2):459-467.

12. Westhorpe RN, Ludbrook GL, Helps SC: Crisis management during anaesthesia: bronchospasm. Qual Saf Health Care 2005, 14(3):e7.

13. Martin DE, Rosenberg H, Aukburg SJ, Bartkowski RR, Edwards MW Jr, Greenhow DE, Klineberg PL: Low-dose fentanyl blunts circulatory responses to tracheal intubation. Anesth Analg 1982, 61(8):680-684.

14. Knoll H, Ziegeler S, Schreiber JU, Buchinger H, Bialas P, Semyonov K, Graeter T, Mencke T: Airway injuries after one-lung ventilation: a comparison between double-lumen tube and endobronchial blocker: a randomized, prospective, controlled trial. Anesthesiology 2006, 105(3):471-477.

15. Lange M, Frommer M, Redel A, Trautner H, Hampel J, Kranke P, Kehl F, Scholtz LU, Roewer N: Comparison of the Glidescope and Airtraq optical laryngoscopes in patients undergoing direct microlaryngoscopy. Anaesthesia 2009, 64(3):323-328.

16. Mikuni I, Suzuki A, Takahata O, Fujita S, Otomo S, Iwasaki H: Arytenoid cartilage dislocation caused by a double-lumen endobronchial tube. $\mathrm{Br} J$ Anaesth 2006, 96(1):136-138.

17. Mencke T, Echternach M, Plinkert PK, Johann U, Afan N, Rensing $H$ Noeldge-Schomburg G, Knoll H, Larsen R: Does the timing of tracheal intubation based on neuromuscular monitoring decrease laryngeal injury? A randomized, prospective, controlled trial. Anesth Analg 2006, 102(1):306-312.

18. Stout DM, Bishop MJ, Dwersteg JF, Cullen BF: Correlation of endotracheal tube size with sore throat and hoarseness following general anesthesia. Anesthesiology 1987, 67(3):419-421.

19. Benjamin B: Laryngeal trauma from intubation: endoscopic evaluation and classification. In Otolaryngology \& Head \& Neck Surgery. Edited by Cummings CW FJ. Mosby: St. Louis; 2001:2013-2035. 
20. Han XD, Lin Z: Comparison of modified and conventional methods in orotracheal intubetion of GlideScope videolaryngoscope. Zhejiang Da Xue Xue Bao Yi Xue Ban 2010, 39(1):89-92.

21. Hsu HT, Chou SH, Chen CL, Tseng KY, Kuo YW, Chen MK, Cheng Kl: Left endobronchial intubation with a double-lumen tube using direct laryngoscopy or the Trachway(R) video stylet. Anaesthesia 2013, 68(8):851-855.

doi:10.1186/1471-2253-14-72

Cite this article as: Hsu et al:: A modified technique to improve the outcome of intubation with a left-sided double-lumen endobronchial tube. BMC Anesthesiology 2014 14:72.

\section{Submit your next manuscript to BioMed Central and take full advantage of:}

- Convenient online submission

- Thorough peer review

- No space constraints or color figure charges

- Immediate publication on acceptance

- Inclusion in PubMed, CAS, Scopus and Google Scholar

- Research which is freely available for redistribution 